\title{
ĐẶC ĐIỂM LÂM SÀNG KÍCH ĐộNG Ở BÊ̂NH NHÂN TÂM THẦN PHÂN LIẸT
}

\section{Nguyễn Đức Vượng ${ }^{2}$, Nguyễn Văn Tuấn ${ }^{2}$, Nguyễn Kim Việt ${ }^{1}$}

\section{TÓM TẮT}

Đặt vấn đề: Bệnh tâm thần phân liệt có diễn biến phức tạp, thường xuyên kèm theo kích động ở bệnh nhân mới nhập viện và có thể xảy ra xuyên suốt toàn bộ quá trình của bênh. Kích động nếu không được xử trí kịp thời có thể dẫn đến tình trạng gây hấn, bạo lực, bênh nhân có hành vi nguy hiểm đối với bản thân và người xung quanh, thậm chí là giết người hoặc tự sát. Mục tiêu: Mô tả đặc điểm lâm sàng kích động ở bệnh nhân tâm thần phân liệt. Phương pháp nghiên cứu: Nghiên cứu cắt ngang trên 83 bệnh nhân có kích động trong 456 bệnh nhân được chẩn đoán động tâm thần phân liệt điều trị nội trú tại Bệnh viện Tâm Thần Hà Nội. Kểt quả: Tỷ lệ kích động chung ở bệnh nhân TTPL là 18,20\%. Các triệu chứng trước cơn kích động: Lo lắng chiếm tỷ lệ 73,49\%; Cáu gắt gặp ở 69,88\% bệnh nhân. $51,81 \%$ bệnh nhân bồn chồn, cảm thấy không thể ngồi môt chỗ. Lâm sàng kích động ở bệnh nhân TTPL: mất khả năng tập trung $(83,13 \%)$; nói nhanh, ồn ào quá mức $(63,85 \%)$; bồn chồn $(60,24 \%)$; bất hợp tác, chống lại sự chăm sóc khắt khe $(66,26 \%)$.

Tư khóa: kích động, tâm thần phân liệt.

\section{SUMMARY \\ CLINICAL OF AGITATION IN PATIENTS WITH SCHIZOPHRENIA}

Background: Schizophrenia has a complicated course, often accompanied by agitation in newly admitted patients and can occur throughout the entire course of the disease. Agitation, if not handle in time, can lead to aggression, violence, the patient has dangerous behavior towards himself and others, even murder or suicide. Objectives: Describe clinical features of agitation in patients with schizophrenia. Method: Cross-sectional study on 83 patients with agitation out of 456 inpatient patients who are diagnosed with schizophrenia at Hanoi Mental Hospital. Results: The overall rate of agitation in schizophrenic patients was $18.20 \%$. Symptoms before agitation: Anxiety accounted for $73.49 \%$; Irritability was observed in $69.88 \%$ of patients. $51.81 \%$ of patients were ataxia and unable to sit still. Clinical agitation in schizophrenic patients: distraction $(83.13 \%)$; fast speaking, excessively noisy $(63.85 \%)$; restlessness $(60.24 \%) ; \quad$ uncooperative, against rigorous care $(66.26 \%)$

Keywords: agitation, schizophrenia.

\footnotetext{
${ }^{1}$ Trường Đại học Y Hà Nội

²Bệnh viện Tâm Thần Hà Nội

Chịu trách nhiệm chính: Nguyễn Đức Vượng

Email: ths.nguyenvuong@gmail.com

Ngày nhận bài: 10.8 .2021

Ngày phản biện khoa học: 4.10.2021

Ngày duyệt bài: 12.10.2021
}

\section{I. ĐĂT VẤN ĐỀ}

Tâm thân phân liệt là một bệnh loạn thân nặng, tiến triển, có khuynh hướng mạn tính, làm cho người bệnh dân dân tách khỏi cuộc sống bên ngoài, thu dần vào thế giới bên trong. Tình cảm trở nên khô lạnh dân, khả năng làm việc, học tập ngày một sút kém, có những hành vi, ý nghĩ kỳ dị, khó hiểu. Tâm thân phân liệt khá phổ biến ở các nước trên thế giới với tỷ lệ khoảng 0,3-0,5\% dân số. Kích động là một tập hợp không cụ thể các hành vi không liên quan được đặc trưng do vận động hoặc hoạt động bằng lời nói quá mức, cáu kỉnh, bất hợp tác, bộc phát giọng nói, cử chỉ đe dọa và hành hung. Kích động xuất hiện trong nhiêu bệnh cơ thể và tâm thân như tẩm thân phân liệt, rối loạn cảm xúc lưỡng cực và sa sút trí tuệ.

Tại Việt Nam, các nghiên cứu chủ yếu về đặc điểm các hành vi nguy hiểm như bạo lực, tự sát, yếu tố pham tội và tập trung nhiều hơn vào hành vi gây hấn trong khi tỷ lệ kích động rất cao ở khoa tâm thân. Nghiên cứu làm rõ đặc điểm của kích động ở bệnh nhân tâm thân phẩn liệt, giúp giảm gánh nặng chăm sóc cho gia đình và xã hội.

Mục tiêu nghiên cứu: Mô tả đặc điểm lâm sàng kích động ở bệnh nhân tâm thần phân liệt.

II. ĐỐI TƯợNG VÀ PHƯƠNG PHÁP NGHIÊN CỨU

1. Đối tượng nghiên cứu: 83 bệnh nhân TTPL có kích động trên tổng số 456 bệnh nhân điều trị nội trú tại Bệnh viện Tâm thân Hà Nội từ tháng 08 - 2020 đến tháng 08 - 2021.

* Tiêu chuẩn lựa chọn: Tất cả bệnh nhân được chẩn đoán TTPL thể paranoid theo tiêu chuẩn chẩn đoán của Tổ chức Y tế Thế giới (ICD-10).

*Tiêu chuẩn loại trừ: Bệnh nhân mắc bệnh cơ thể nặng hoặc nghiện chất. Bệnh nhân khiếm thính, khiếm thị, chậm phát triển trí tuệ. Bệnh nhân và gia đình không đồng ý tham gia nghiên cứu.

\section{Phương pháp nghiên cứu.}

*Thiết kế nghiên cứu:

- Mô tả chùm ca bệnh đặc điểm lâm sàng kích động ở bệnh nhân TTPL.

- Các hành vi kích động được đánh giá theo thang PANSS-EC, gồm 5 mục: kích động (P4), thù địch (P7), căng thẳng (G4), không hợp tác (G8) và kiểm soát xung động kém (G14). Bệnh nhân có kích động khi điểm PANSS-EC $\geq 14$, và có ít nhất một mục có điểm số $\geq 4^{1}$. 
*Xử lý số liệu: bằng phần mềm thống kê SPSS 20.0 .

\section{KẾT QUẢ NGHIÊN CỨU VÀ BÀN LUÂN 1. Đặc điểm chung của nhóm đối tượng nghiên cứu}

Bảng 3. 1. Đăc điểm nhân khẩu học

\begin{tabular}{|c|c|c|c|}
\hline \multicolumn{2}{|c|}{ Đăc điếm } & $\mathbf{n}$ & $\%$ \\
\hline \multirow{2}{*}{$\begin{array}{c}\text { Nhóm } \\
\text { tuổi }\end{array}$} & $\leq 30$ & 18 & 21,69 \\
\hline & $>30$ & 65 & 78,31 \\
\hline \multirow{2}{*}{ Giới } & Nam & 49 & 59,04 \\
\hline & Nữ & 34 & 40,96 \\
\hline \multirow{4}{*}{$\begin{array}{l}\text { Trình độ } \\
\text { học vấn }\end{array}$} & Tiểu học & 8 & 9,64 \\
\hline & Trung học cơ sở & 31 & 37,35 \\
\hline & $\begin{array}{c}\text { Trung học phố } \\
\text { thông }\end{array}$ & 36 & 43,37 \\
\hline & $\begin{array}{c}\text { Đại học/ Sau Đại } \\
\text { học }\end{array}$ & 8 & 9,64 \\
\hline \multirow{3}{*}{$\begin{array}{l}\text { Nghêe } \\
\text { nghiệp }\end{array}$} & Tự do & 11 & 13,25 \\
\hline & Không nghề & 63 & 75,90 \\
\hline & Nghề khác & 9 & 10,84 \\
\hline \multirow{4}{*}{$\begin{array}{l}\text { Hôn } \\
\text { nhân }\end{array}$} & Độc thân & 50 & 60,24 \\
\hline & Kết hôn & 21 & 25,30 \\
\hline & Ly thân/ Ly hôn & 11 & 13,26 \\
\hline & Góa & 1 & 1,20 \\
\hline \multirow{2}{*}{$\begin{array}{l}\text { Nơi } \\
\text { sống }\end{array}$} & Nông thôn & 42 & 50,60 \\
\hline & Thành thị & 41 & 49,40 \\
\hline
\end{tabular}

Tuối trung bình của nhóm bệnh nhân nghiên cứu là 38,08 $\pm 11,02$ tuổi. Có thể bệnh nhân TTPL kèm theo kích động thường được điều trị trong thời gian dài, vì vậy tuổi trung bình cao hơn những bệnh nhân TTPL nói chung. Nam giới chiếm tỷ lệ 59,04\%; tương đồng với kết quả trong nghiên cứu của Weifeng Mi và Zhang với tỷ lệ nam bệnh nhân TTPL có kích động là $51,07 \%$ và $51,0 \% 2,3$.

Bệnh nhân có trình độ THPT và THCS chiếm chủ yếu với tỷ lệ là $43,37 \%$ và $37,35 \%$. Tuổi khởi phát của bệnh nhân TTPL thường gặp trước 20 tuổi nên họ có trình độ học vấn tương đương độ tuổi. Nếu bệnh không tiến triển nặng và liên tục thì bênh nhân vẫn có thể học tiếp được. Số bệnh nhân thất nghiệp chiếm tỷ lệ cao nhất, 75,9\%; có thể liên quan đến trình độ học vấn thấp trong nhóm bệnh nhân nghiên cứu của chúng tôi.

Đa số bệnh nhân đang độc thân chiếm 60,24\%; có 25,3\% bệnh nhân đã kết hôn và hiện đang sống cùng vợ/chồng và $13,26 \%$ bệnh nhân đã ly hôn hoặc đang sống ly thân. Bệnh TTPL thường khởi phát khi tuổi còn khá trẻ, đa số khi bệnh nhân chưa lập gia đình. Một tỷ lệ nhất định khởi phát khi bệnh nhân đã lập gia đình nhưng có thể những mâu thuẫn phát sinh do tính chất bệnh lý dẫn đến ly hôn hoặc ly thân.
Vì vậy, ở nhiều nghiên cứu về bệnh TTPL cho thây tỷ lệ độc thân cao.

\section{Lâm sàng kích động ở bênh nhân TTPL} 2.1. Tỷ lê kích đông ở bênh nhân TTPL

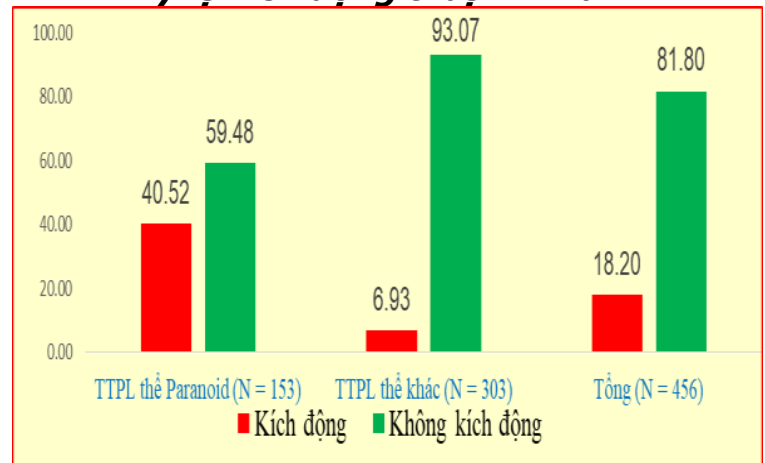

Biểu đồ 3.1. Tỷ lệ kích động ở bệnh nhân TTPL

Trong khoảng thời gian nghiên cứu, có 456 bệnh nhân TTPL vào điều trị nội trú tại bệnh viện Tẩm thần Hà Nội với tỷ lệ kích động là $18,20 \%$. Tỷ lệ kích động ở bênh nhân TTPL thể Paranoid là 40,52\%, ở các thể bênh TTPL khác chỉ chiếm $6,93 \%$. Weifeng Mi nghiên cứu quan sát đa trung tâm tính phổ biến của kích động trong bệnh nhân TTPL tai 14 bệnh viên ở Trung Quốc và thây tỷ lệ chung kích động là 47,50\%; dao động từ 27,07\% đến $88,21 \%$ ở các bệnh viện khác nhau 2 .

2.2. Đặc điểm triệu chứng lâm sàng trước trạng thái kích động

Bảng 3.2. Tỷ lệ triệu chứng báo trước trạng thái kích động $(N=83)$

\begin{tabular}{|c|c|c|}
\hline Triêu chứng & $n$ & $\%$ \\
\hline $\begin{array}{l}\text { Lo lắng (đố mồ hôi, tăng } \\
\text { thông khí, run,..) }\end{array}$ & 61 & 73,49 \\
\hline Cáu gắt & 58 & 69,88 \\
\hline $\begin{array}{l}\text { Nhạy cảm/ Căng thẳng về thể } \\
\text { chất - cơ bắp }\end{array}$ & 34 & 40,96 \\
\hline $\begin{array}{l}\text { Thiếu hợp tác thụ động (thách } \\
\text { thức) }\end{array}$ & 24 & 28,92 \\
\hline $\begin{array}{c}\text { Biểu hiện đau khố về thể chất/ } \\
\text { cảm xúc (đau đớn) }\end{array}$ & 18 & 21,69 \\
\hline $\begin{array}{l}\text { Lời nói lặp đi lặp lại, tông } \\
\text { giọng cao/ nặng lời }\end{array}$ & 53 & 63,86 \\
\hline $\begin{array}{c}\text { Thái độ thù địch (nóng tính/ } \\
\text { không hợp tác) }\end{array}$ & 40 & 48,19 \\
\hline $\begin{array}{c}\text { Bồn chồn/ cảm thấy không thể } \\
\text { ngồi một chố }\end{array}$ & 43 & 51,81 \\
\hline $\begin{array}{l}\text { Hung hăng/ gầy hấn lời nói } \\
\text { (lăng mạ/ đe dọa) }\end{array}$ & 23 & 27,71 \\
\hline $\begin{array}{c}\text { Thái độ khó chịu (lời nói ác ý, } \\
\text { thô tục, xúc phạm) }\end{array}$ & 43 & 51,81 \\
\hline $\begin{array}{c}\text { Gây hấn/ gây tình trạng lộn } \\
\text { xộn (đóng sầm cửa) }\end{array}$ & 30 & 36,14 \\
\hline Tự làm đau/ hủy & 6 & 7,22 \\
\hline
\end{tabular}


Trước cơn kích động, bệnh nhân TTPL thường có các triệu chứng: Lo lắng (đổ mồ hôi, tăng thông khí, run,..) chiếm tỷ lệ $73,49 \%$; Cáu gắt gặp ở 69,88\% bệnh nhân. 63,86\% bệnh nhân có tông gionng cao/ nặng lời hoặc lời nói lặp đi lặp lại. $51,81 \%$ bệnh nhân bồn chồn, cảm thấy không thể ngồi một chỗ hoặc có thái độ khó chịu, lời nói ác ý, thô tục, xúc phạm. Bệnh nhân gây tình trạng lộn xộn, đóng sầm cửa $(36,14 \%)$ hoặc đe dọa bằng lời nói $(27,71 \%)$. 7,22\% bệnh nhẩn có hành vi tự gây đau. Chúng tôi nhận thây các triệu chứng báo trước trạng thái kích động không xuất hiện riêng lẻ mà một bệnh nhân có thể có nhiều triệu chứng khác nhau cùng xuất hiện. Có thể thấy các hành vi có tần suất chiếm tỷ lệ cao là biểu hiện lo lắng kèm theo triệu chứng rối loạn thần kinh tự trị, cáu gắt, bồn chồn, khó thư giãn, nói âm điệu cao, nặng lời,..

Whittington thấy rằng các hành vi bạo hành bằng lời nói, chửi thề, tăng hoạt động, đứng ngồi không yên, giọng nói lớn và giao tiếp bằng mắt trừng trừng được thấy hơn một nửa số bênh nhân trong khoảng 5 phút trước khi xảy ra hành vi tấn công. Không có hành vi nào đặc trưng xuất hiện ở tất cả các bệnh nhân trong thời gian này và triệu chứng dự đoán tốt nhất là lạm dụng bằng lời nói như ồn ào, lăng mạ, tức giận hoặc thù địch,... xuất hiện trong $2 / 3$ số trường hợp 4 . Ogloff đánh giá các yếu tố nguy cơ gây hấn trong 24h tiếp theo ở bệnh nhân tâm thần điều trị nội trú, thấy tỷ lệ bệnh nhân có triệu chứng cáu gắt là $70,5 \%$; bốc đồng: $54,5 \%$; không muốn làm theo hướng dẫn: $34,1 \%$; nhạy cảm với sự khiêu khích: 43,2\%; dễ dàng tức giận khi yêu cầu bị từ chối: $38,6 \%$; thái độ tiêu cực: $50,0 \%$; đe dọa bằng lời nói: $51,2 \%{ }^{5}$.

3.2.2.3. Đặc điểm lâm sàng trong trạng thái kích động

Bảng 3.3. Tỷ lê triệu chứng trong trạng thái kích động $(N=83)$

\begin{tabular}{|c|c|c|}
\hline Triệu chứng & $\mathbf{n}$ & $\%$ \\
\hline $\begin{array}{l}\text { Khoảng chú ý ngắn, mất khả } \\
\text { năng tập trung }\end{array}$ & 69 & 83,13 \\
\hline $\begin{array}{l}\text { Bốc đồng, thiếu kiên nhần, khả } \\
\text { năng chịu đựng thất vọng thấp }\end{array}$ & 51 & 61,45 \\
\hline $\begin{array}{l}\text { Bất hợp tác, chống lại sự chăm } \\
\text { sóc, khắt khe }\end{array}$ & 55 & 66,26 \\
\hline $\begin{array}{l}\text { Bạo lực và/ hoắc đe dọa bạo lực } \\
\text { đổi với người hoặc tài sản }\end{array}$ & 22 & 26,51 \\
\hline $\begin{array}{l}\text { Bùng nố và/ hoặc tức giâan } \\
\text { không thể đoán trước }\end{array}$ & 48 & 57,83 \\
\hline Lang thang, ra khỏi khu vực điều trị & 32 & 38,55 \\
\hline $\begin{array}{l}\text { Sự bồn chồn, nhịp độ, di chuyến } \\
\text { quá mức }\end{array}$ & 50 & 60,24 \\
\hline
\end{tabular}

\begin{tabular}{|c|c|c|}
\hline Các hành vi/ lời nói lặp đi lặp lại & 25 & 30,12 \\
\hline Nói nhanh/ ôn ào quá mức & 53 & 63,85 \\
\hline $\begin{array}{c}\text { Thay đối tâm trạng đột ngột/ } \\
\text { Cảm xúc không ồn định }\end{array}$ & 21 & 25,30 \\
\hline $\begin{array}{c}\text { Dê dàng bắt đâuu hoă̆c khóc và/ } \\
\text { hoăcc cười quá mức }\end{array}$ & 14 & 16,87 \\
\hline $\begin{array}{c}\text { Tự ngược đãi bản thân, thế chất } \\
\text { và// hoặc bằng lời nói }\end{array}$ & 9 & 10,84 \\
\hline
\end{tabular}

Lâm sàng kích động ở bệnh nhân TTPL thấy các triệu chứng thường gặp trong kích động là khoảng chú ý ngắn/ mất khả năng tập trung $(83,13 \%)$; nói nhanh hoặc ồn ào quá mức $(63,85 \%)$. Bệnh nhân thường bồn chồn/ di chuyển quá mức $(60,24 \%)$; bất hợp tác, chống lại sự chăm sóc, khắt khe $(66,26 \%)$ và bốc đồng, thiếu kiên nhẫn, khả năng chịu đựng thất vong thấp $(61,45 \%)$. Bùng nổ và/ hoặc tức giận không thể đoán trước chiếm $57,83 \%$. Cảm xúc không ổn định/ thay đổi đột ngột chiếm 25,3\%. Bao lực và/ hoă̆c đe dọa bạo lực đối với người hoặc tài sản chiếm $26,51 \%$. Tự ngược đãi bản thân, thế chất và/ hoặc bằng lời nói chiếm tỷ lệ thất nhất, $10,84 \%$.

George và $\mathrm{CS}$ thây kích động bằng lời nói chiếm $51,85 \%$, gồm đe dọa bằng lời nói, khóc thật to, la hét, nói ồn ào, ngôn ngữ lạm dụng,.. $48,1 \%$ bênh nhân bồn chồn, tăng nhịp độ; $20,4 \%$ từ chối ăn/ thức ăn; 20,3\% cố gắng rời khỏi buồng bệnh không có sự cho phép, 25,9\% đánh người khác và $16,6 \%$ có hành vi tự làm tổn thương bản thân ${ }^{6}$. Vieta $\mathrm{E}$. và $\mathrm{CS}$ mô tả trạng thái kích động tâm thần vận động gồm: Hành vi không phù hợp, không có mục đích rõ ràng; Tăng tính kích thích; Không có khả năng giữ yên lặng, ngồi hoặc bình tĩnh; Khí sắc căng thẳng và biểu hiện giận dữ; Giong điệu cao, im lặng hoặc từ chối giao tiếp; Thay đổi trạng thái cảm xúc với biểu hiện lo lắng, cáu kỉnh hoặc thù địch; Gây hấn bằng lời nói và/ hoặc thể chất, chống lại bản thân hoặc những người khác hoặc đồ vật;...

Mức độ nghiêm trọng của kích động diễn ra theo một chuối liên tục dẫn đến gây hấn và bạo lực. Bệnh nhân có thể tăng ngôn ngữ và / hoặc hành vi đơn điê̂u. Như hành vi/ chuyển động lặp lại, phàn nàn, yêu cầu chú ý, mặc quần áo không phù hợp hoăcc cởi quần áo,..., Với cường độ cao hơn biểu hiện bằng ngôn ngữ nặng lời, la hét hoặc chửi rủa) và hành vi đi lang thang liên tục và không mục đích, đi vào đi ra nơi không thích hợp,.. cho đến các hành vi gây hấn như đe dọa bằng lời nói, đánh, xô đẩy, cào cấu, cắn, ném các đồ vật,... có thể chạm tới mức độ nguy hiểm cao nhất như cố ý làm tổn thương bản thân hoặc người khác, hủy hoại tài sản, cố gắng tự sát 
hoặc giết người.

Bảng 3.4. Tỷ lệ loại kích động ( $N=83)$

\begin{tabular}{|c|c|c|}
\hline Loai kích đông & n & $\%$ \\
\hline Kích động ngôn ngữ & 73 & 87,95 \\
\hline Kích đông tâm thần vân đông & 49 & 59,03 \\
\hline \multicolumn{3}{|c|}{ Kích động tâm thần vận động } \\
\hline Đập phà & 31 & 37,35 \\
\hline & 9 & 10,84 \\
\hline & 9 & 10.84 \\
\hline
\end{tabular}

Nguyễn Quang Ngọc Linh phân loại hành vi kích động thây bệnh nhân có kích động lời nói chiếm $96,55 \%$, đập phá đồ đạc chiếm $55,17 \%$, có 1 bệnh nhân $(1,72 \%)$ có hành vi tấn công bản thân ${ }^{8}$. George và CS nghiên cứu mô hình và mối tương quan kích động ở bệnh nhân tâm thần cấp tính thấy các dạng kích động phổ biến nhất phối hợp kích động ngôn ngữ và hành vi không mục tiêu và thấp nhất là kích động hành vi có mục tiêu'.

Từ kết quả các nghiên cứu cho thấy, kích động ngôn ngữ chiếm tỷ lệ cao nhất, hành vi tấn cổng người khác và hủy hoại bản thân chiếm tỷ lệ thấp nhất. Theo ghi nhận của chúng tôi, những bệnh nhân này kích động do tức giận, khó chịu với sự xuất hiện liên tục và nội dung của ảo thanh nên không kiểm soát được bản thân, khác với hành vi do ảo thanh ra lệnh hoặc hoang tưởng chi phối trong bệnh TTPL.

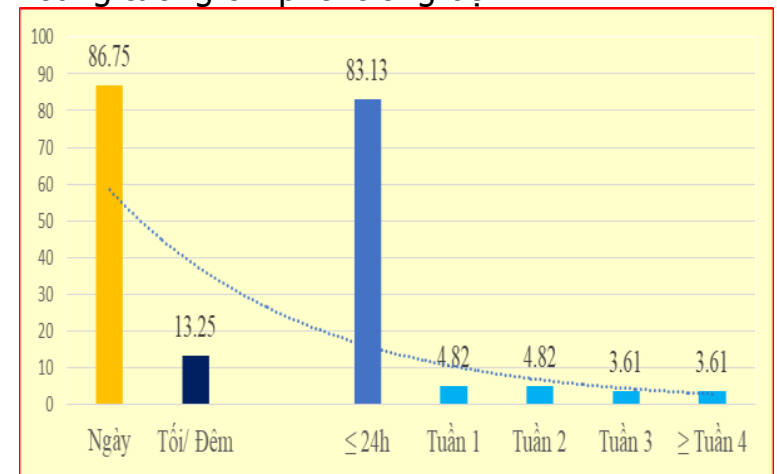

Biểu đồ 3.2. Thời điểm kích động ở bệnh nhân TTPL

Thời điểm kích động thường xảy ra vào ban ngày chiếm tỷ lệ $86,75 \%$ và trong ngày đầu nhập viện $(83,13 \%)$, giảm dần ở các tuần điều trị tiếp theo. Có thể do đối tượng của chúng tôi là bệnh nhân điều trị nội trú, tại địa điểm nghiên cứu, phần lớn thuốc chống loạn thần được chia liêu cao hơn vào buổi tối nên phần nào làm giảm tỷ lệ kích động xảy ra vào ban đêm. George và CS khảo sát 272 bệnh nhân tâm thần nội trú và nhận thấy kích động có nhiều khả năng xảy ra vào ngày thứ hai hoặc thứ ba sau ngày nhập viện ${ }^{6}$.

\section{KẾT LUÂ̂N}

- Tỷ lệ kích động chung ở bệnh nhân TTPL là 18,20\%; ở bệnh nhân TTPL thể Paranoid là $40,52 \%$ và TTPL thể khác là $6,93 \%$. Thời điểm kích động thường xảy ra vào ban ngày, chiếm tỷ lệ $86,75 \%$ và trong thời điểm nhập viện $(83,13 \%)$.

- Các triệu chứng trước cơn kích động: Lo lắng (đổ mồ hôi, tăng thông khí, run,..) chiếm tỷ lệ 73,49\%; Cáu gắt gặp ở 69,88\% bệnh nhân. $63,86 \%$ bệnh nhân có tông giọng cao/ nặng lời. $51,81 \%$ bệnh nhân bồn chồn, cảm thấy không thể ngồi một chỗ. 7,22\% bệnh nhân có hành vi tự gây đau.

- Lâm sàng kích động ở bệnh nhân TTPL: mất khả năng tập trung $(83,13 \%)$; nói nhanh, ồn ào quá mức $(63,85 \%)$; bồn chồn $(60,24 \%)$; bất hợp tác, chống lại sự chăm sóc khắt khe $(66,26 \%)$; bốc đồng, thiếu kiên nhẫn $(61,45 \%)$. Tự ngược đãi bản thân chiếm tỷ lệ 10,84\%.

\section{TÀI LIỆU THAM KHẢO}

1. Sacchetti E., Amore M., Sciascio G.D. Psychomotor agitation in psychiatry: an Italian Expert Consensus. Evidence-based Psychiatric Care. 2017;3:1-24.

2. Weifeng Mi, Suzhen Zhang, Qi Liu, et al. Prevalence and risk factors of agitation in newly hospitalized schizophrenia patients in China: An observational survey. Psychiatry research. Jul 2017;253:401-406.

doi:10.1016/j.psychres.2017.02.065

3. Zhang SZ, Mu YG, Liu $\mathbf{Q}$, et al. Prescription practices in the treatment of agitation in newly hospitalized Chinese schizophrenia patients: data from a non-interventional naturalistic study. BMC Psychiatry. Jul $10 \quad 2019 ; 19(1): 216$. doi:10.1186/s12888-019-2192-6

4. Whittington $\mathbf{R}$, Patterson $\mathbf{P}$. Verbal and nonverbal behavior immediately prior to aggression by mentally disordered people: enhancing the assessment of risk. J Psychiatr Ment Health Nurs. $1996 ; 3(1): 47-54 . \quad$ doi:10.1111/j.1365-2850. 1996.tb00191.x

5. Ogloff JR, Daffern M. The dynamic appraisal of situational aggression: an instrument to assess risk for imminent aggression in psychiatric inpatients. Behav Sci Law. 2006;24(6):799-813. doi:10.1002/bsl.741

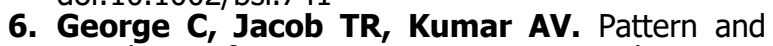
correlates of agitation in an acute psychiatry inpatient setting in a teaching hospital. Asian Journal of Psychiatry. Feb 2016;19:68-72. doi: 10.1016/ j.ajp.2015.11.010

7. Vieta E, Garriga M, Cardete $L$, et al. Protocol for the management of psychiatric patients with psychomotor agitation. BMC Psychiatry. 2017/09/ 08 2017;17(1):328. doi:10.1186/s12888-017-1490-0

8. Nguyễn Quang Ngọc Linh. Đặc điểm lâm sàng rối loạn hành vi ở bệnh nhân tẩm thân phân liệt thể Paranoid. Đại học Y Hà Nội; 2018. 